\title{
WAVE OVERTOPPING DATABASE AS THE STARTING POINT FOR A NEURAL NETWORK PREDICTION METHOD
}

\author{
H. Verhaeghe ${ }^{1}$, J. W. van der Meer ${ }^{2}$, G.-J. Steendam², \\ P. Besley ${ }^{3}$, L. Franco ${ }^{4}$, M. Van Gent ${ }^{5}$
}

\begin{abstract}
The EU project CLASH (EVK3-CT-2001-00058) (Jan. 2002 Dec. 2004), stands for 'Crest Level Assessment of coastal Structures by full scale monitoring, neural network prediction and Hazard analysis on permissible wave overtopping' (www.clash-eu.org). One of the objectives of CLASH is to produce a generally applicable prediction method for wave overtopping at coastal structures based on permissible wave overtopping and hazard analysis.

The set up of a homogeneous database on wave overtopping is one of the main tasks within the framework of CLASH and is the main subject of this paper. On the one hand, the database gives a detailed inventory of overtopping tests which have been performed and on the other hand, the database serves as the starting point for a neural network prediction method.

At this moment (Dec. 2003), the overtopping database consists of more than 6500 overtopping tests. This paper gives a complete overview of the contents of the database and discusses the methodology.
\end{abstract}

\section{INTRODUCTION}

At this moment no universal prediction method for wave overtopping at coastal structure exists. Several overtopping formulae do exist, but these formulae are only applicable to a limited range of structure configurations, see Van der Meer et al. (1998) for dikes, Franco et al. (1994) for vertical walls and Besley et al. (1998) for shallow water conditions.

The CLASH-project intends to fill the deficit of a generally applicable overtopping formula by creating a generic prediction method with the aid of artificial

neural networks. As the application of the neural network technique requires a huge amount of existing overtopping information to train the network, one of the main tasks within the CLASH - project is the set up of a large homogeneous database

${ }^{1}$ Ghent University, Dept. of Civil Engineering, Technologiepark 904, B-9052 Ghent, Belgium, hadewych.verhaeghe@ugent.be, tel +32 92645489, fax +3292645837

${ }^{2}$ Infram, PO Box 81, Patroonsweg 29, 3892 AB Zeewolde, The Netherlands, jentsje.vandermeer@,infram.nl, gosse.jan.steendam@infram.nl, tel +31 365218020, fax +31527241119

${ }^{3} \mathrm{HR}$ Wallingford, Howberry Park, Wallingford, Oxon OX10 8BA, UK, phil@,hrwallingford.co.uk, tel +44 1491822230, fax +44 1491825539

${ }^{4}$ MODIMAR, via Montezebio 40, 00915 Rome, IT, 1.franco@modimar.it, tel +390632694623, fax +390632694629

${ }^{5}$ WL Delft Hydraulics, PO Box 177, Rotterdamseweg 185, $2600 \mathrm{MH}$ Delft, The Netherlands, marcel.vangent@,wldelft.nl, tel +31 152858846, fax +31 152858582 
consisting of overtopping test results.

Existing data sets on overtopping are gathered therefore from universities and research institutes all over the world. These data are partly originating from partners within CLASH, but also data from elsewhere in Europe and worldwide (e.g. USA, Japan) contribute to the database. It concerns generic tests as well as site specific overtopping tests, and this at all kinds of coastal structures.

The confidentiality of the database is guaranteed to the data providers, implicating that for confidential tests, it is not possible to trace the data, not even for CLASH partners. For free data (e.g. data of research projects) a reference is given in the database to the origin of the data. This makes it possible to the users of the database to study details of the tests.

An overview of the origin of the gathered overtopping tests at this moment is given in table 1 (Verhaeghe et al. (2003)):

Table 1 Overview of origin of overtopping tests

\begin{tabular}{lr} 
Institute (Country) & Number of tests \\
\hline Aalborg University (Denmark) & 476 \\
Danish Hydraulic Institute (Denmark) & 96 \\
Delft Hydraulics (The Netherlands) & 1165 \\
Hydraulic Research Wallingford (United Kingdom) & 1896 \\
Leichtweiss Institut für Wasserbau (Germany) & 691 \\
Modimar (Italy) & \\
$\quad$ Estramed-laboratories & 177 \\
$\quad$ University of Florence & 479 \\
$\quad$ Enel-Hydro & 247 \\
University of Edinburgh (United Kingdom) & 359 \\
Universidad Politécnica de Valencia (Spain) & 153 \\
Others & \\
$\quad$ (Iceland) & 39 \\
$\quad$ (Japan) & 367 \\
(Norway) & 22 \\
(USA) & 354 \\
\hline & 6521
\end{tabular}

\section{GENERAL METHODOLOGY FOR OVERTOPPING DATABASE}

The first phase in the methodology to come to a database consists of gathering as much overtopping test results as possible. Establishing a reliable database requires detailed information on the overtopping tests. It has to be stressed that the reliability of the database is all the more important as the database will be used for the development of a neural network.

Therefore, in a second phase, each particular dataset is screened carefully on consistency. This is done by analysing the original reports: not only information about the wave characteristics, the overtopping structure and corresponding overtopping is gathered, but also information concerning the test facility, the processing of the measurements and the precision of the work is searched for. To 
account for the effect of reliability in the database, a 'reliability-factor' is defined for each test. Values from 1 to 4 can be assigned to this factor, standing for 'very reliable' up to 'not reliable'.

In the third phase, all gathered information is included in the database by means of a fixed number of parameters. The parameters are chosen in such a way that an as complete overview as possible of the overtopping tests is represented. At the same time it is tried to limit the number of parameters, as a neural network only can consist of a restricted number of input parameters depending on the number of tests that are available. Consequently some complex geometries are not considered e.g. crest dissipation basins.

Distinction can be made between hydraulic information (incident wave characteristics, measured overtopping volume), structural information (test section characteristics) and additional general information (reliability of the test, complexity of the structure).

Finally, each test is incorporated in the database by means of 31 parameters of which 11 hydraulic parameters, 17 structural parameters and 3 general parameters. Tables 2, 3 and 4 give an overview of these 31 parameters in the database.

Table 2 Overview of the hydraulic parameters in the database

\begin{tabular}{|c|c|c|}
\hline 1 & $\mathrm{H}_{\mathrm{m} 0 \text { deep }}[\mathrm{m}]$ & $\begin{array}{l}\text { Significant wave height from spectral analysis }=4 \sqrt{m_{0}}{ }^{(*)} \text {, at deep } \\
\text { water }\end{array}$ \\
\hline 2 & $\mathrm{~T}_{\mathrm{p} \text { deep }}[\mathrm{s}]$ & Peak period from spectral analysis at deep water \\
\hline 3 & $\mathrm{~T}_{\mathrm{m} \text { deep }}[\mathrm{s}]$ & Mean period from spectral analysis at deep water $=\mathrm{m}_{2} / \mathrm{m}_{0}{ }^{(*)}$ \\
\hline 4 & $\mathrm{~T}_{\mathrm{m}-1,0 \text { deep }}[\mathrm{s}]$ & Mean period from spectral analysis at deep water $=\mathrm{m}_{-1} / \mathrm{m}_{0}{ }^{(*)}$ \\
\hline 5 & $\beta\left[^{\circ}\right]$ & Angle of wave attack relative to the normal on the structure \\
\hline 6 & $\mathrm{H}_{\mathrm{m} 0 \text { toe }}[\mathrm{m}]$ & $\begin{array}{l}\text { Significant wave height from spectral analysis }=4{\sqrt{m_{0}}}^{(*)} \text { at the } \\
\text { toe of the structure }\end{array}$ \\
\hline 7 & $\mathrm{~T}_{\mathrm{p} \text { toe }}[\mathrm{s}]$ & Peak period from spectral analysis at the toe of the structure \\
\hline 8 & $\mathrm{~T}_{\mathrm{m} \text { toe }}[\mathrm{s}]$ & $\begin{array}{l}\text { Mean period from spectral analysis at the toe of the structure } \\
=\mathrm{m}_{2} / \mathrm{m}_{0}^{\left({ }^{*}\right)}\end{array}$ \\
\hline 9 & $\mathrm{~T}_{\mathrm{m}-1,0 \text { toe }}[\mathrm{s}]$ & $\begin{array}{l}\text { Mean period from spectral analysis at the toe of the structure } \\
=\mathrm{m}_{-1} / \mathrm{m}_{0}^{\left({ }^{*}\right)}\end{array}$ \\
\hline 10 & $\mathrm{q}\left[\mathrm{m}^{3} / \mathrm{s} . \mathrm{m}\right]$ & Overtopping volume per second per meter width \\
\hline 1 & $\mathrm{P}_{\text {ow }}[-]$ & Percentage of the waves resulting in overtopping \\
\hline
\end{tabular}

Sometimes not all of the 31 parameters are mentioned in the corresponding report of the test. Therefore, in a fourth phase, additional calculations are performed and/or assumptions are made to determine the missing parameters. These calculations and assumptions also have an influence on the reliability of a test. 
Table 3 Overview of the structural parameters in the database (see figure 1)

\begin{tabular}{|c|c|c|}
\hline 1 & $\mathrm{~h}_{\text {deep }}[\mathrm{m}]$ & Water depth at deep water \\
\hline 2 & $\mathrm{~m}[-]$ & Slope of the foreshore \\
\hline 3 & $\mathrm{~h}[\mathrm{~m}]$ & Water depth at the toe of the structure \\
\hline 4 & $\mathrm{~h}_{\mathrm{t}}[\mathrm{m}]$ & Water depth on the toe of the structure \\
\hline 5 & $\mathrm{~B}_{\mathrm{t}}[\mathrm{m}]$ & Width of the toe of the structure \\
\hline 6 & $\gamma_{\mathrm{f}}[-]$ & Roughness/permeability factor for the structure \\
\hline 7 & $\cot \alpha_{d}[-]$ & Cotangent of the slope of the structure downward of the berm \\
\hline 8 & $\cot \alpha_{\mathrm{u}}[-]$ & Cotangent of the slope of the structure upward of the berm \\
\hline 9 & $\cot \alpha_{\text {excl }}[-]$ & $\begin{array}{l}\text { Mean cotangent of the slope of the structure, without contribution } \\
\text { of the berm }\end{array}$ \\
\hline 10 & $\cot \alpha_{\text {incl }}[-]$ & $\begin{array}{l}\text { Mean cotangent of the slope of the structure, with contribution of } \\
\text { the berm }\end{array}$ \\
\hline 11 & $\mathrm{R}_{\mathrm{c}}[\mathrm{m}]$ & Crest freeboard of the structure \\
\hline 12 & $\mathrm{~B}[\mathrm{~m}]$ & Width of the berm \\
\hline 13 & $\mathrm{~h}_{\mathrm{b}}[\mathrm{m}]$ & Water depth on the berm \\
\hline 14 & $\tan \alpha_{\mathrm{B}}[-]$ & Tangent of the slope of the berm \\
\hline 15 & $\mathrm{~B}_{\mathrm{h}}[\mathrm{m}]$ & Width of the horizontally schematised berm \\
\hline 16 & $\mathrm{~A}_{\mathrm{c}}[\mathrm{m}]$ & Armour crest freeboard of the structure \\
\hline 17 & $\mathrm{G}_{\mathrm{c}}[\mathrm{m}]$ & Width of the structure crest \\
\hline
\end{tabular}

Table 4 Overview of the general parameters in the database

\begin{tabular}{l|ll}
1 & Name & $\begin{array}{l}\text { This parameter assigns a unique name to each test } \\
2\end{array}$ \\
RF [-] & $\begin{array}{l}\text { The 'Reliability Factor' gives an indication of the reliability of the } \\
\text { test. }\end{array}$ \\
CF [-] & $\begin{array}{l}\text { The 'Complexity Factor' gives an indication of the complexity of } \\
\text { the test structure. }\end{array}$
\end{tabular}

At this moment the database consists of 6521 screened overtopping test results (see table 1), from 132 independent test series.

This first version of the overtopping database will be enlarged in a last phase by more gathered data from institutions all over the world and extra data to be gathered within CLASH: prototype measurements, results of prototype reproduction on scale models, results of additional parametric model tests and extra model tests to fill up the white spots of the database. The mentioned prototype measurements are established at 3 coastal overtopping sites in Europe: Zeebrugge, Belgium (from 1999 on), Ostia, Italy (from 2003 on) and Samphire Hoe, UK (from 2003 on).

This will lead to a completed homogeneous database, which will form the basis of the final generic prediction method. 


\section{DETERMINING THE PARAMETERS OF THE DATABASE}

\section{Hydraulic parameters}

The 11 hydraulic parameters of each test (see table 2) describe the waves at deep water. The hydraulic parameter $\mathrm{q}$ is chosen here to describe the overtopping phenomenon and not the parameters describing maximum discharge per wave or distribution of the discharge. The reason for this is that these last parameters, although also important parameters, are only available for a few tests. The directional spreading parameter is not considered since only a few tests are available with multidirectional waves and it is assumed that directional spreading has little effect on overtopping.

In the first neural network approach, the network will be developed with only four of the above mentioned hydraulic parameters: $\mathrm{H}_{\mathrm{m} 0 \text { toe }}, \mathrm{T}_{\mathrm{m}-1,0}$ toe, $\mathrm{b}$ and $\mathrm{q}\left[\mathrm{m}^{3} / \mathrm{s} . \mathrm{m}\right]$. It is therefore important that these four parameters are known for each test. Anyway, both for the completeness of the database and the later possibilities to extend the neural network with other input parameters, it is aimed for to determine all the hydraulic parameters for each test. Frequently appearing cases in which extra calculations and/or estimations are needed are the following:

case1: $\quad \mathrm{T}_{\mathrm{m}-1,0}$ is missing

case2: $\quad$ all incident wave parameters at the toe of the structure are missing $\left(\mathrm{H}_{\mathrm{m} 0 \text { toe, }} \mathrm{T}_{\mathrm{p} \text { toe }}, \mathrm{T}_{\mathrm{m} \text { toe }}\right.$ and $\left.\mathrm{T}_{\mathrm{m}-1,0 \text { toe }}\right)$

case 3: $\quad \mathrm{H}_{\mathrm{m} 0 \text { toe }}$ is missing

(in this last case the significant wave height from time analysis just in front of the structure, $\mathrm{H}_{1 / 3}$ toe, is available)

In the first case, the missing parameter is determined, assuming following relationship:

$$
\mathrm{T}_{\mathrm{m}-1,0}=\mathrm{T}_{\mathrm{p}} / 1.1
$$

This proportion is only valid for single-peaked spectra at deep water, what implicates that one has to be careful with this estimation. Depending on the degree of wave breaking at the location where formula (1) is utilised, the factor implementing the reliability is set lower or higher (more breaking $=$ less reliable $=$ higher value of the reliability factor).

In the second case, the wave parameters at the toe of the structure are determined from those at deep water with the aid of the numerical wave modelling program SWAN. The program SWAN is developed at the Technical University of Delft and stands for Simulating WAves Nearshore. It is based on the energy balance. As most overtopping tests which have been included in the database concern longcrested waves or normal wave attack, the two-dimensional version of SWAN, which is easier to handle than the three-dimensional version, is used.

The input for SWAN are the wave characteristics at deep water (significant wave height and mean or peak period at deep water) together with the exact foreshore (in one dimension). SWAN yields the wave characteristics at the toe of the structure. 
The total number of SWAN calculations made for the first database is about 1600 . That is more than $25 \%$ of all overtopping tests. As SWAN calculations are less reliable than measured wave characteristics, the reliability factor of tests with SWAN calculations is also adapted to this fact.

In the third case, the wave height $\mathrm{H}_{1 / 3}$ toe is available instead of $\mathrm{H}_{\mathrm{m} 0}$ toe. Here the method of Battjes \& Groenendijk (2000) is used to determine the wanted parameter $\mathrm{H}_{\mathrm{m} 0 \text { toe }}$. Battjes \& Groenendijk give a prediction method for the local wave height distribution on shallow foreshores for a given local water depth, bottom slope and total wave energy. Using the water depth at the toe of the structure, the bottom slope and the given wave height $\mathrm{H}_{1 / 3}$ toe as input for Battjes \& Groenendijk, the output is the total wave energy $\mathrm{m}_{0}$, from which we can easily calculate the wanted wave height $\mathrm{H}_{\mathrm{m} 0 \text { toe. }}$ Also here, the reliability factor is adapted to the calculation fact.

In some tests it happens that the wave characteristics are only available at the toe of the structure and not at deep water. As it is not possible to make a good estimation of the corresponding deep water wave characteristics, the value of the deep water wave characteristics is not filled in into the database in these cases. If the neural network wants to be trained with the wave characteristics at deep water, these data will have to be left out.

\section{Structural parameters}

The 17 structural parameters are chosen in order to be able to describe most structures adequately by these and only these parameters. They are summarized in table 3.

Figures 1 shows a cross-section of a rubble mound breakwater with 15 structural parameters marked.

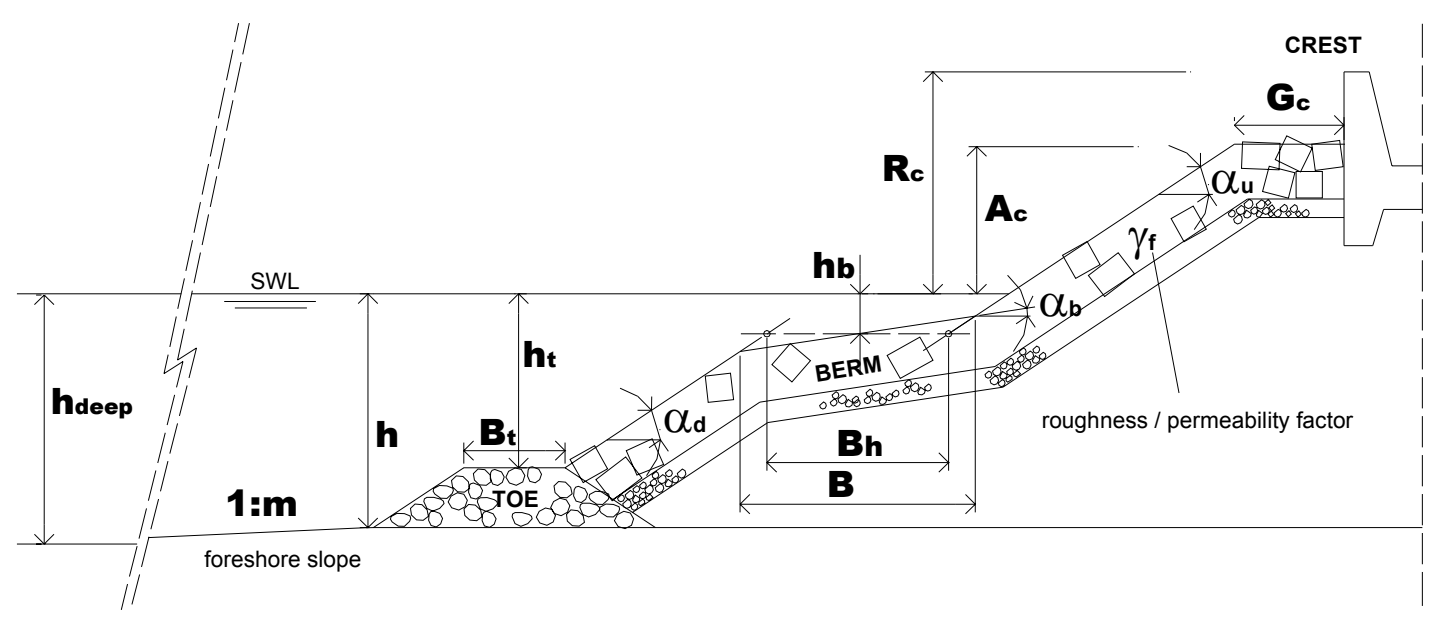

Figure 1: Structural parameters

The two structural parameters which are not on figure 1 are calculated 'mean' values for the structure slope: $\alpha_{\text {incl }}$ and $\alpha_{\text {excl }}$. The parameter $\alpha_{\text {incl }}$ stands for a mean structure slope in which the contribution of an eventual berm of the structure is included. The 
parameter $\alpha_{\text {excl }}$ stands for a mean structure slope in which the contribution of an eventual berm of the structure is excluded. They can be determined as follows (see figure 2):

$$
\cot \alpha_{\text {incl }}=\mathrm{H} / \mathrm{V} \quad \text { and } \quad \cot \alpha_{\mathrm{excl}}=\left(\mathrm{H}-\mathrm{B}_{\mathrm{h}}\right) / \mathrm{V}
$$

with:

$\mathrm{H}=$ horizontal distance between the point on the upper slope, $1.5 \mathrm{H}_{\text {m0toe }}$ above SWL (point $r$ ) and the point on the down slope, $1.5 \mathrm{H}_{\mathrm{m} 0 \text { toe }}$ below $\mathrm{SWL}$ (point s)

$\mathrm{V}=\quad$ vertical distance between point $\mathrm{r}$ and point $\mathrm{s}$

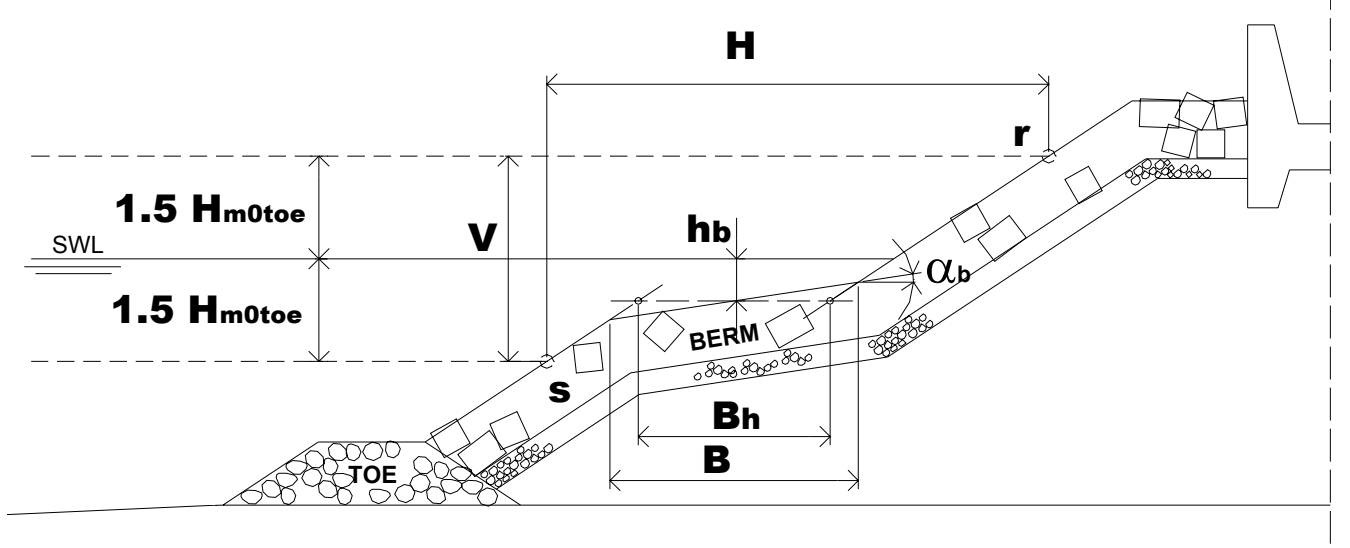

Figure 2: Determination of the parameters $\cot \alpha_{\text {incl }}$ and $\cot \alpha_{\text {excl }}$

It has to be mentioned that the crest and toe of the structure may not be included in these slope definitions, implicating that the points $r$ and $s$ have to be situated under the crest respectively above the toe.

In the first neural network approach, only 11 structural parameters will be used: $h$, $B_{t}, h_{t}, B_{h}, h_{b}, \cot \alpha_{d}, \cot \alpha_{u}, \gamma_{f}, R_{c}, A_{c}$ and $G_{c}$. In a later stage maybe more or other parameters of the 17 mentioned structural parameters will be used. Anyway, it is aimed to determine for each overtopping test all of the 17 structural parameters. Difficulties which appear are:

1) In some cases some parameters are missing:

Parameters which are sometimes not included into the corresponding report of a test, are the deep water depth $h_{\text {deep }}$ and the foreshore slope $m$. When it is not possible to retrieve these values, they are not filled in into the database. When the neural network wants to be trained with the deep water characteristics, these data should be omitted.

2) In some cases a schematisation of the cross-section has to be made:

Some overtopping tests are performed with very complicated cross-sections, resulting in the fact that the cross-section is too difficult to be described by the 17 structural parameters which are chosen here. In these cases the cross-sections are approximated and the structural parameters are determined on this approximated section. The effect of this loss of information of the cross-section is accounted for by 
a complexity-factor which is assigned to each test. Values from 1 to 4 can be assigned to this factor, standing for 'very simple section' respectively 'too complicated section'.

\section{General parameters}

The general parameters (see table 4) are related to general information about the overtopping tests. A first parameter 'name' assigns a unique name to each tests, just to handle the data in the database. The parameters ' $\mathrm{CF}$ ', standing for complexityfactor, and 'RF', standing for reliability-factor, are representative for the complexity respectively the reliability of the test. As already mentioned, CF as well as RF can adopt values from 1 (very easy section respectively very reliable test) to 4 (very complicated section respectively unreliable test).

Tests with $\mathrm{RF}=4$ or $\mathrm{CF}=4$ are incorporated in the overtopping database, but will not be used for the training of the neural network as the corresponding tests are not reliable enough for this. This reduces the number of tests which are useful for the neural network from 6521 to 5893 .

\section{CONTENTS OF OVERTOPPING DATABASE}

At this moment a first screened overtopping database consisting of 6521 overtopping tests from 132 test series is finished. Each overtopping test is included in the database by means of 31 parameters.

Figure 3 shows a plot of all tests with the dimensionless wave overtopping discharge $\frac{q}{\sqrt{g H_{m 0}^{3}}}$ as a function of the relative crest freeboard $\mathrm{R}_{\mathrm{c}} / \mathrm{H}_{\mathrm{m} 0}$ toe. Tests with $\mathrm{q}=0 \mathrm{~m}^{3} / \mathrm{s} . \mathrm{m}$ are not included in the figure.

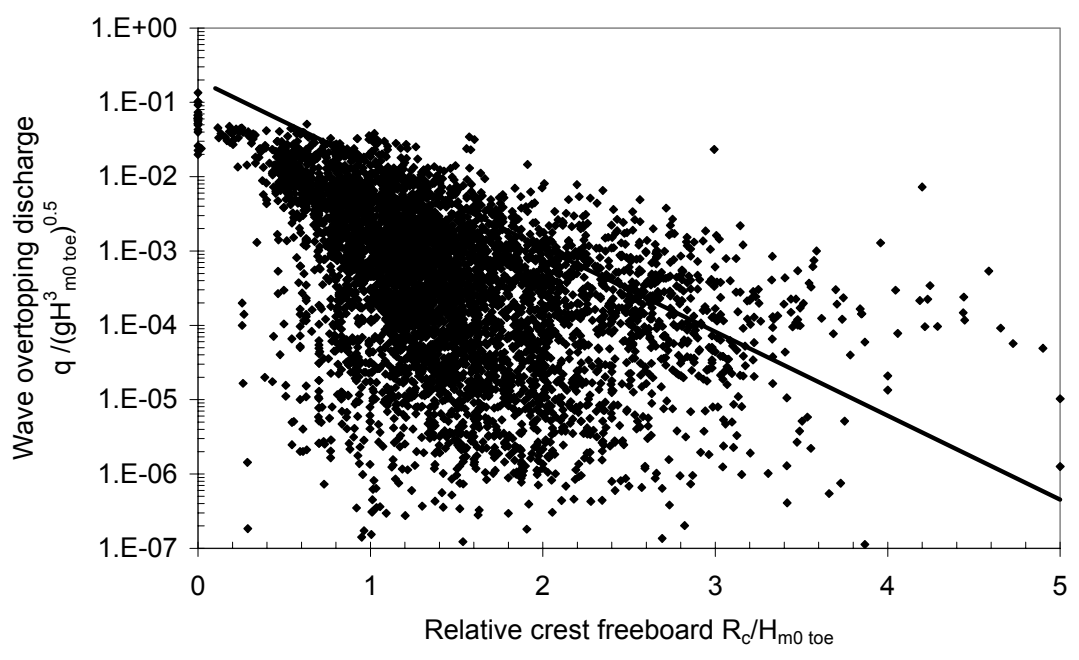

Figure 3: Dimensionless plot of all overtopping tests

For comparison the existing empirical TAW formula (2002) for overtopping at dikes is given by the black line (non-breaking waves): 


$$
\frac{q}{\sqrt{g H_{m 0}^{3}}}=0.2 . \exp \left(-2.6 \cdot \frac{R_{c}}{H_{m 0}} \cdot \frac{1}{\gamma_{f} \cdot \gamma_{\beta}}\right)
$$

with:

- $\mathrm{q}=$ overtopping discharge $\left[\mathrm{m}^{3} / \mathrm{s} / \mathrm{m}\right]$

$-\mathrm{H}_{\mathrm{m} 0}=$ significant wave height at the toe of the structure [m]

$-\mathrm{R}_{\mathrm{c}}=$ crest freeboard with respect to Still Water Level [m]

- $g_{f}, g_{b}=$ influence factors for roughness and angle of wave attack respectively [-]

This graph is only mentioned to give an idea of the contents of the database, it is up to the neural network to find relationships between the parameters in the database.

As the database will be used as input for a neural network, the spreading of the parameters is important. It has to be mentioned here that a neural network can only make reliable predictions in the parameter ranges it has been trained on. Extra model tests performed within the framework of CLASH will have to fill up important missing parameter ranges, the so called 'white spots', in the database.

Figures 4 to 8 give examples of the contents and the spreading of the parameters in the database.

Figures 4 and 5 show the wave steepness versus the wave height at the toe of the structure. Figure 4 shows all test data. Wave heights larger than $0.3 \mathrm{~m}$ can be considered as large scale tests. The small scale tests are shown in figure 5.

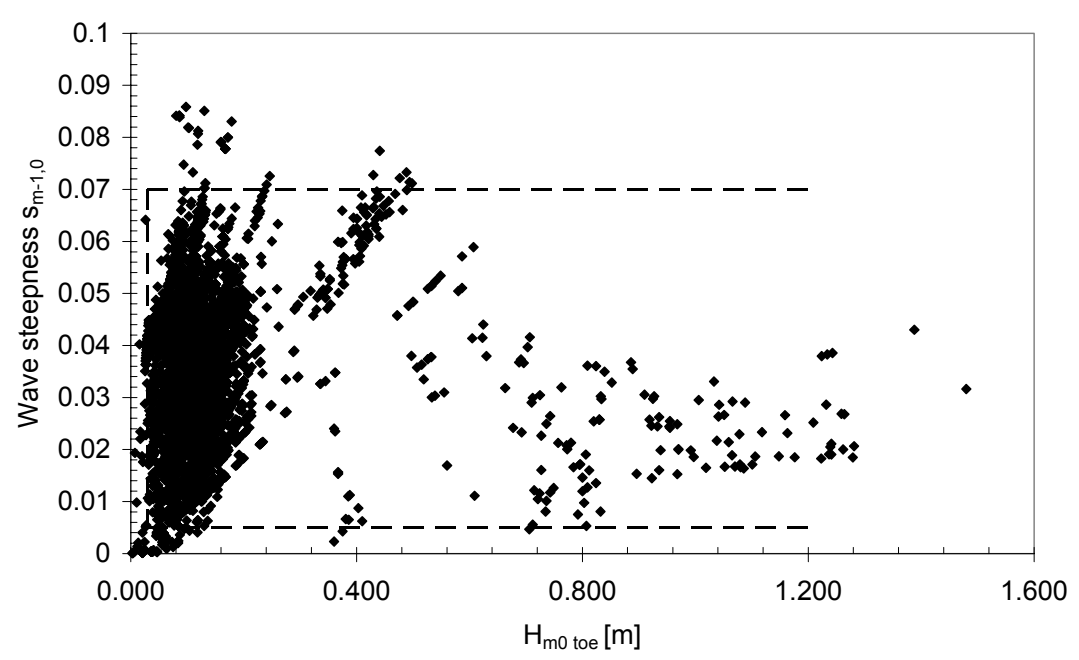

Figure 4: Wave steepness $\mathrm{s}_{\mathrm{m}-1,0}$ versus $\mathrm{H}_{\mathrm{m} 0}$ toe, all tests

The lines on the figures mark the area with most reliable tests. A wave steepness larger than 0.07 is physically not possible, the waves break on steepness. Wave steepness' smaller than 0.005 are difficult to generate in a flume and wave heights smaller than $0.03 \mathrm{~m}$ are less reliable. The (rather few) tests lying outside the marked area are therefore given a lower reliability-factor. 


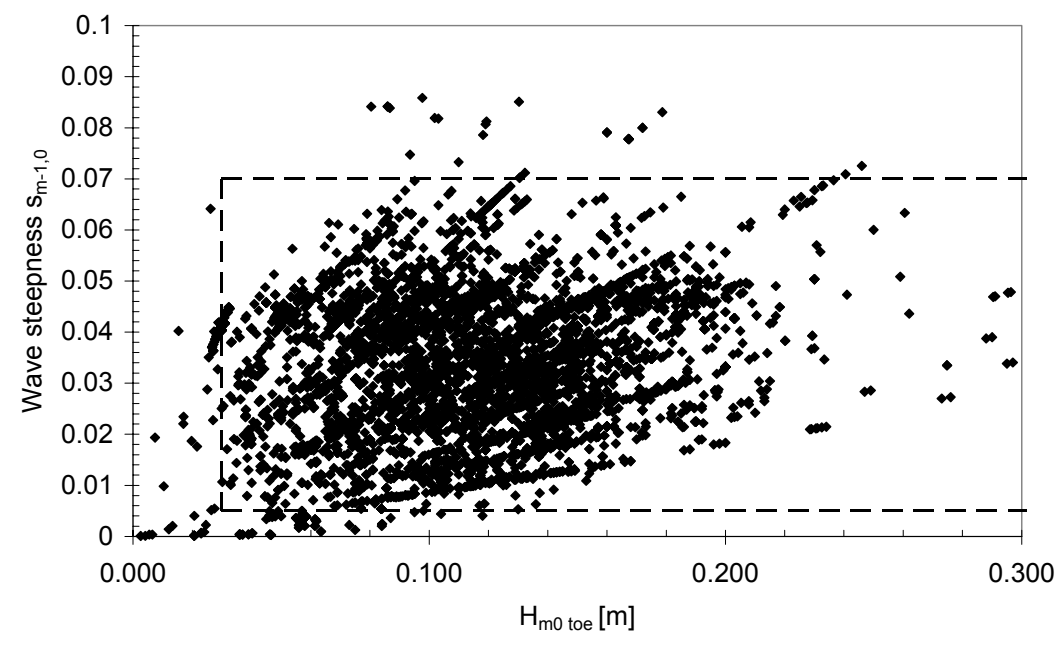

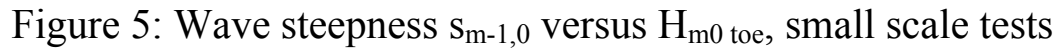

Figure 6 shows the angle of wave attack versus the wave height at the toe of the structure. Only small scale tests are available with oblique wave attack. As there are good arguments to believe that for very oblique wave attack long-crested waves do not simulate nature in a proper way, long-crested oblique tests with $\mathrm{b}>45^{\circ}$ were given $\mathrm{RF}=4$. As can be seen on the figure, only a small number of the 6521 tests concern oblique wave attack. The influence of oblique wave attack on wave overtopping is one of the white spots to be considered.

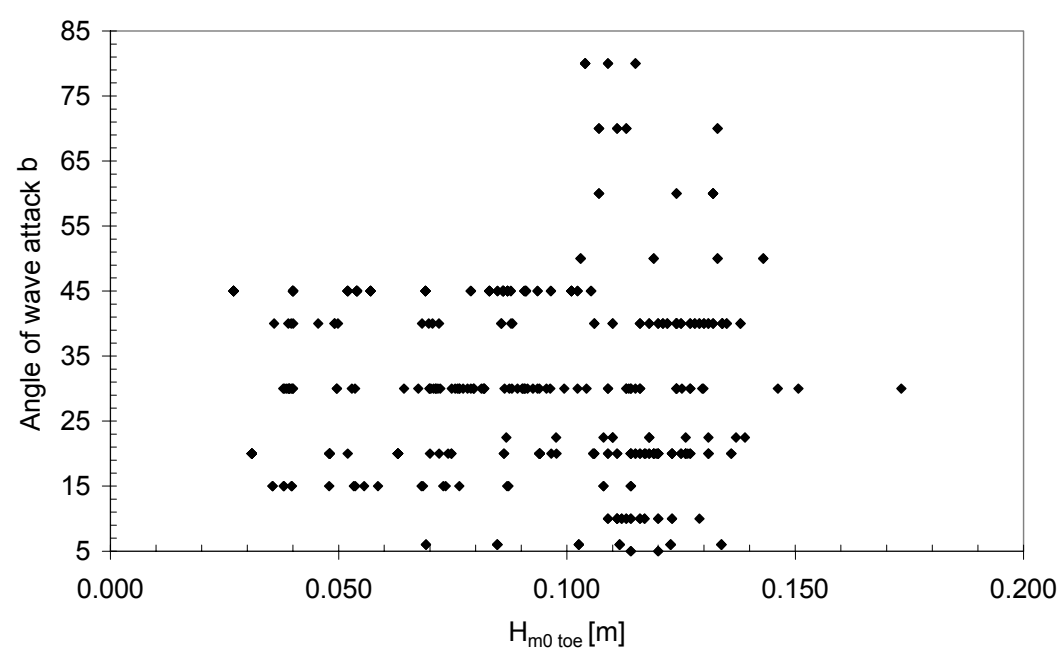

Figure 6: Angle of wave attack b versus $\mathrm{H}_{\mathrm{m} 0}$ toe

The roughness factor is given versus the down slope in figure 7. Three roughness factors are used more frequently than others: 1 (smooth), 0.55 (2 layers of rock) and 0.4 (concrete armour units). Others are estimations of roughness factors, including other effects such as wave return walls. Roughness is well covered in the range $0<\cot \alpha_{\mathrm{d}}<4$ and $0.4<\mathrm{g}_{\mathrm{f}}<1$. 


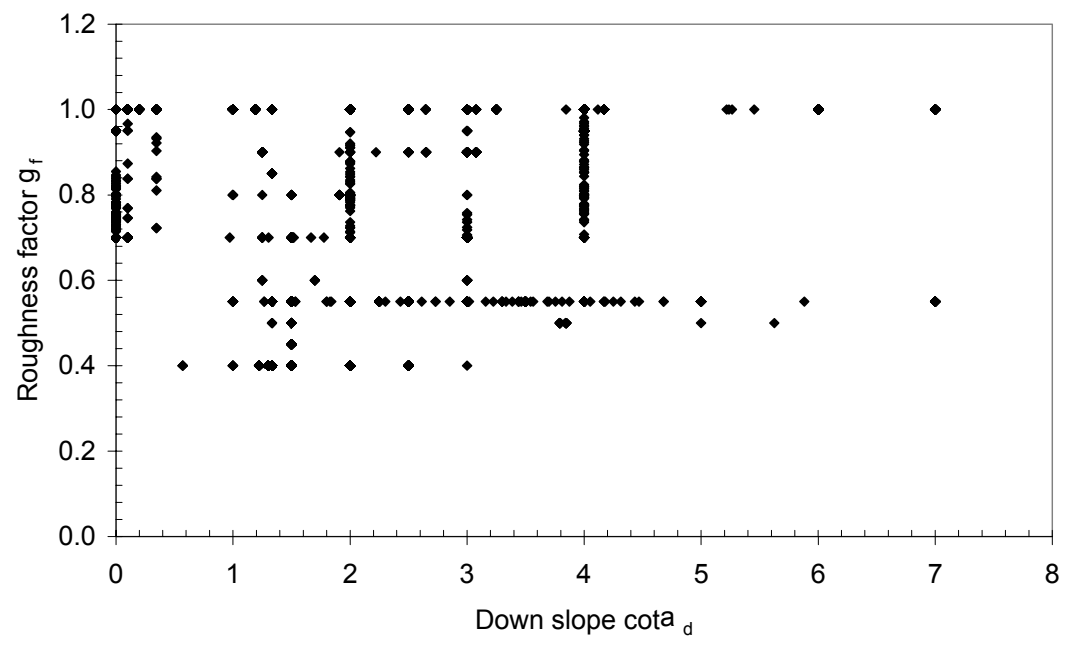

Figure 7: Roughness factor $g_{f}$ versus down slope $\cot \alpha_{d}$

It should be mentioned, however, that all concrete units were given the value $g_{f}=0.4$. White spot tests should give the correct values for a number of concrete unit types.

Figure 8 shows the upper slope of the structure versus the down slope of the structure. Most test series have similar upper and down slopes, but not all of them. A number of test series have a down slope and a vertical upper slope (points on horizontal axis). This can be with or without a berm. Other tests have a vertical down slope and an upper slope, but there are only a few (points on vertical axis). The area covered quite well can be described by $1<\cot \alpha_{d}<6$ with $0<\cot \alpha_{u}<6$.

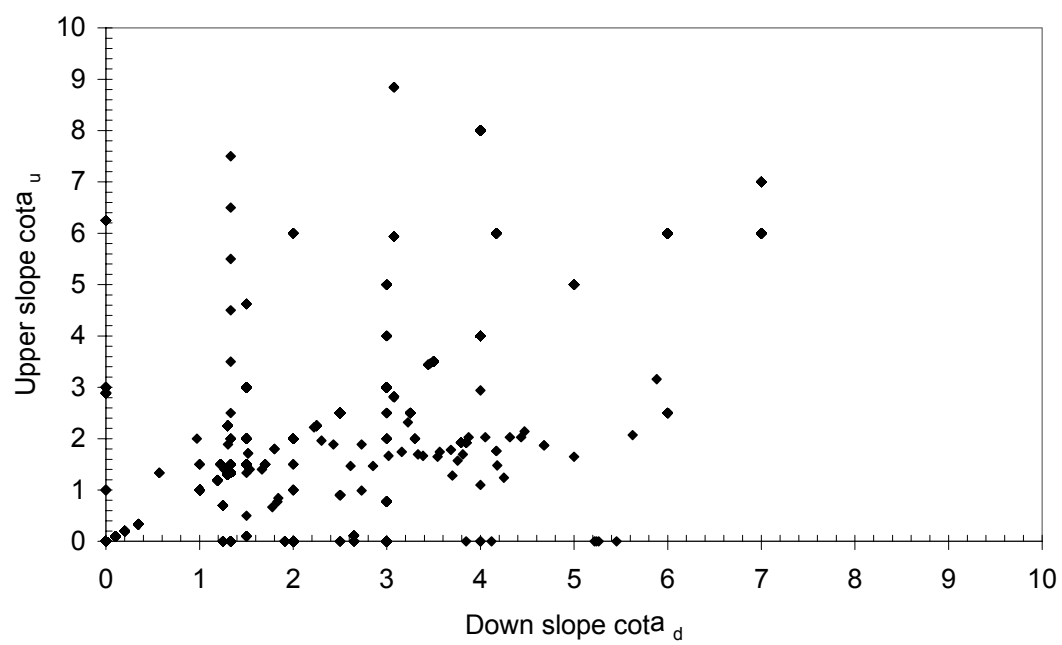

Figure 8: Upper slope $\cot \alpha_{u}$ versus down slope $\cot \alpha_{d}$

The above figures give only an idea of the spreading of some of the parameters. More research on the database learned that the most important white spots can be summarized as: 
- Roughness factor $\gamma_{\mathrm{f}}$ for different armour units

- Oblique wave attack

- Influence of the roughness around SWL

- Influence of $\mathrm{G}_{\mathrm{c}}$ and $\mathrm{A}_{\mathrm{c}}$

- Angle of the berm

- Toe details

Additional parametric tests within the CLASH-project will give additional information on some of these white spots and will lead to a more homogeneous database.

\section{NEURAL NETWORK}

The final goal of the overtopping database is to use it as input for a neural network prediction method. In a first approach, the neural network will be trained with 14 input parameters of which 11 structural parameters $\left(h, B_{t}, h_{t}, B_{h}, h_{b}, \cot \alpha_{d}, \cot \alpha_{u}, g_{f}\right.$, $R_{c}, A_{c}$ and $\left.G_{c}\right)$ and 3 hydraulic parameters $\left(H_{m 0 \text { toe }}, T_{m-1,0}\right.$ toe and $\left.b\right)$. There is only one output parameter: the overtopping discharge $\mathrm{q}$ in $\mathrm{m}^{3} / \mathrm{s}$ per meter width. The parameters $\mathrm{CF}$ and $\mathrm{RF}$ will be combined together to one value per test, corresponding to a weight-factor for the test. This implicates that a very reliable test $(\mathrm{RF}=1)$ with simple cross-section $(\mathrm{CF}=1)$ will be used several times more as input during training of the neural network than a less reliable test $(\mathrm{RF}=3)$ with difficult cross-section $(\mathrm{CF}=3)$.

Figure 9 shows the general structure of a first approach neural network for overtopping at coastal structures. The input will be optimized during the development of the neural network.

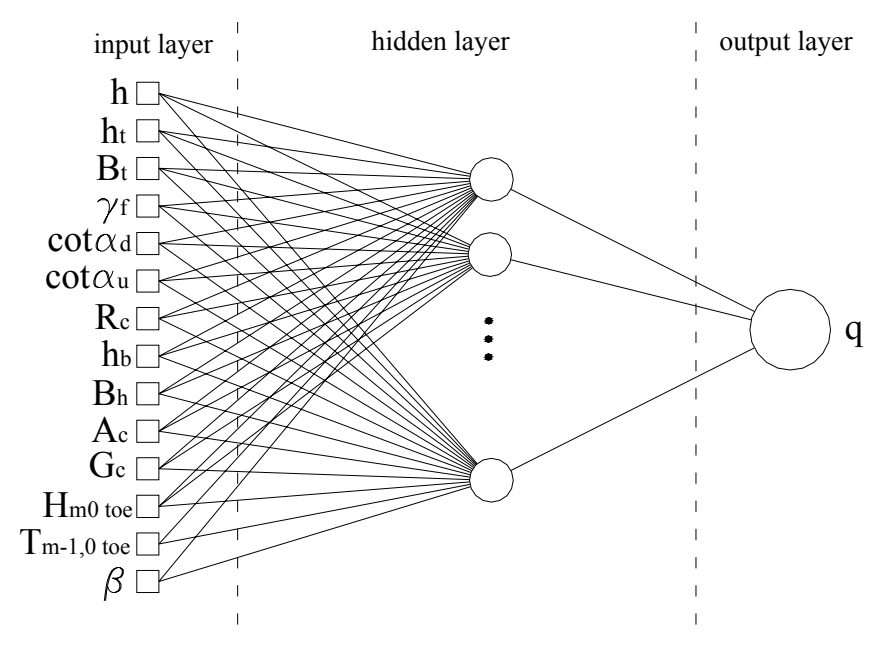

Figure 9: General structure of a first approach neural network

\section{CONCLUSIONS}

A first overtopping database has been finished halfway the second year of the CLASH-project (July 2003). At this moment (Dec. 2003) it is only available for CLASH partners. For non-confidential overtopping tests a reference to the origin of 
the data is available, for confidential data not. With this database the development of a neural network has been started already, which will lead to a first generic prediction method in the beginning of the third year of the CLASH-project (beginning of 2004).

The first database is enlarged at this moment. The enlargement of the database started in August 2003 and will last until July 2004. The extra data consist of more gathered data from institutions all over the world and extra data to be gathered within CLASH: prototype measurements, results of prototype reproduction on scale models, results of additional parametric model tests and extra model tests to fill up white spots.

In July 2004 a final completed database will be available together with the final prediction method, adapted to this final database. Both will be available for all interested.

On behalf of establishing guidelines for crest level design for seawalls and related sea defence structures, various levels of allowable overtopping discharge will be fixed. This will be done based on hazard analysis. The guidelines will be available at the end of the project (December 2004).

\section{ACKNOWLEDGEMENT}

The CLASH project EVK3-CT-2001-00058 frames within the EESD programme of the Fifth Framework Programme of the EU. The financial contribution of the European Community is therefore very much acknowledged. The technical contributions of all those who have provided data are also gratefully acknowledged. Regarding the numerous institutions who have delivered data it is impossible to list all names.

\section{REFERENCES}

Battjes, J.A. \& Groenendijk, H.W., (2000). Wave height distributions on shallow foreshores, Coastal Engineering 40, p161-182.

Besley, P., Stewart, T. and Allsop, N.W.H., (1998). Overtopping of vertical structures: new prediction methods to account for shallow water conditions. Proc. Conf. Coastlines, Structures and Breakwaters, I.C.E., March 1998, publ. Thomas Telford, London.

Franco, L., de Gerloni, M. and Van der Meer, J.W., (1994). Wave overtopping on vertical and composite breakwaters. ASCE, proc. 24th ICCE, Kobe, Japan, pp. 1030-1045.

TAW, (2002). Technisch Rapport Golfoploop en Golfoverslag bij Dijken. (Technical Report on Wave Run -up and Wave Overtopping at Dikes - In Dutch. English version available in 2004). Technical Advisory Committee on Water Defences, Delft, The Netherlands.

Van der Meer, J.W., Tönjes, P. and de Waal, J.P., (1998). A code for dike height design and examination. Proc. Conf. Coastlines, Structures and Breakwaters, I.C.E., pp. 5-19. Ed. N.W.H. Allsop, Thomas Telford, London, UK.

Verhaeghe, H., van der Meer, J.W., Steendam, G.-J., (2003). CLASH: Database on wave overtopping at coastal structures, pp. 34. To be published in 2004. 